\title{
Standards for interactive multimedia services
}

Summary of the SII1 guideline from the ACTS program

Standards are an important issue if services are to work in a multi-provider world. The ACTS multimedia projects have produced a guideline 'State of the Art and Evolution of Relevant Standards' explaining which aspects of multimedia services are being standardised by the various official and semiofficial bodies. It also explains how the various initiatives relate to each other so that potential service developers and providers know where to look for the relevant specifications to ensure interoperabilty.

The principal standards players are:

$$
\begin{aligned}
& \text { - ETSI } \\
& \text { - CENELEC } \\
& \text { - DVB } \\
& \text { - ITU-T } \\
& \text { - ISO/IEC } \\
& \text { - DAVIC } \\
& \text { - ATM Forum } \\
& \text { - W3C } \\
& \text { - IETF } \\
& \text { - OMG } \\
& \text { - ANSI-T1 } \\
& \text { - IEEE } 802
\end{aligned}
$$

and the following sections explore what each of them is doing.

\section{ETSI}

The ETSI activities on multimedia communication are distributed over several Technical Committees, Special Committees and Projects, notably:

- Project MTA (Multimedia Terminals and Applications),

- Project TIPHON (Telecommunication and Internet Protocol Harmonisation Over Networks),

- Project EASI (ETSI project on ATM Services Interoperability),

- Special Committee GMM CG (Global Multimedia Mobility Co-ordination Group),

- Technical Sub-committee NA8 (Network Architectures, Network Interworking, Global Information Infrastructures, Network evolution and related IP matters). 
Recent significant outputs include:

- A draft ETSI Guide on the subject of Multimedia Information Retrieval Services (MIRS), by the HF committee,

- A Technical Report on a reference framework for network architecture and traffic aspects of multimedia communication, from NA5,

- Co-ordination of ETSI multimedia (originally TE 10 but now the MTA project).

\section{CENELEC}

CENELEC is the European standardisation organisation for electrotechnical aspects of equipment and systems. The Technical Committees directly relevant to multimedia are:

TC 203: "Electronic entertainment and educational systems for household and similar use",

TC 206: "Broadcast receiving equipment",

TC 207: "Radio Data System",

TC 209: "Cabled distribution systems for television, sound and interactive multimedia signals",

TC 100X: "Audio, Video and Multimedia Systems and equipment" (this Committee has been recently established, the name is to be confirmed).

\section{$D V B$}

DVB (Digital Video Broadcasting) involves the main European broadcasters, manufacturers, operators, regulatory bodies, administrations, service providers, etc. DVB has been working since 1993, and is producing specifications for Digital Video Broadcasting through the different transmission media:

- Satellite (DVB-S),

- Cable (DVB-C),

- SMATV (DVB-SMATV),

- Terrestrial (DVB-T),

- MMDS (DVB-MS and DVB-MC).

All of which specify signal containers for MPEG 2 streams.

DVB is also working on other aspects of the Digital Broadcasting chain, including Conditional Access, Physical Interfaces, Data Broadcasting, Measurements procedures, etc. A major activity has been the development of specifications for interactive systems.

DVB is driven by commercial interest and that technical specifications are only developed in response to a commercially oriented requirements document. Agreed DVB specifications are submitted to ETSI or CENELEC for formal adoption as European Standards.

\section{$I T U-T$}

ITU-T has a number of Study Groups actively working on multimedia. The most important groups are:

- SG9, studies on distributive services,

- SG11 service and network control aspects (Control Plane),

- SG13 network architecture and traffic aspects (User Plane) and "Global Information Infrastructure" (GII) studies, 
- SG16, overall multimedia studies and, in particular, aspects concerned with services and application related specifications and coding aspects (User and Management plane).

\section{ISO/IEC}

ISO/IEC JTC1/SC29/WG11 looks at audio and video coding aspects.

- MPEG-2: This is a homonym coding scheme, whose hierarchical structure and flexibility will support the development of mass market multimedia services. It is now an international standard.

- MPEG-4: This is a highly efficient object-based coding technique for multimedia applications such as: text and graphics overlays for digital television, broadcasting and Web casting of complex multimedia scenes, Milestones are the Committee Draft (CD) in November 1997, Draft International Standard in July 1998, the International Standard in November 1998.

- MPEG-7: This is a Multimedia Content Description Interface which aims to provide is efficient searching for multimedia content, using standardised descriptions of that content. The standard will include ONLY the description of the content. Milestones are the Call For Proposals Nov. 98, and the Working Draft for July 99. International Draft is expected for Nov. 2000.

- MHEG-5: This aims to define a standard interchange format for multimedia applications running on low-cost terminals. DAVIC has adopted it as the mandatory application format in its 1.0 specifications. A Draft ISO Standard will be released soon.

\section{DAVIC}

DAVIC, the Digital Audio-VIdeo Council, was established relatively recently but is considered to be "the" forum for multimedia. It was created specifically to deal with end-systems and network aspects of multimedia service provision. The first issue of the DAVIC specification, covering the service provision chain from the server to the set-top unit, was published at the end of January 1996. The second issue, covering broadcast and enhanced broadcast services, was finalised in September 1996. DAVIC 1.3 was finalised in March 1997.

DAVIC has a particular interest in security issues and interoperability, to which specific groups are dedicated. Other groups cover applications, transport network aspects, architectural and protocol aspects for control, user and management planes, and coding aspects. The provision of multimedia services over IP-based networks is also being considered.

\section{ATM Forum}

The ATM Forum Technical Committee on Audio-visual Multimedia Services is defining an overall system reference model and specifying technologies and protocols to support the different functionalities. Since the creation of DAVIC, the ATM Forum has concentrated on specifying techniques and protocol layers strictly related to ATM communication, which have since been endorsed by DAVIC. In return the ATM Forum has accepted the DAVIC model and is trying to maximise the harmonisation between the specifications from the two bodies.

\section{W3C}

The World Wide Web Consortium (W3C) is an industry consortium promoting standards for the evolution of the Web and interoperability between WWW products by producing specifications and reference 
software. Although funded by industrial players, it is vendor-neutral and its products are freely available to all. By the summer of 1996, membership had grown to over 150 organisations from all parts of the world.

The current activities are:

- User Interface, covering Hypertext Mark-up Language (HTML), Style Sheets (CSS), Internationalisation, Graphics, and Fonts;

- User Interface Software Products (including Arena and Amaya);

- Technology and Society, covering Content Rating (PICS), Privacy and Demographics, Digital Signatures, Electronic Commerce (JEPI), Intellectual Property Rights, and Access for the Disabled;

- Architecture, covering Addressing (URLs), Protocols (HTTP and HTTP-NG), Distributed Objects and Mobile Code, Real-Time (Audio and Video), Propagation, Replication and Caching, and Generic SGML;

- Architecture Software Products, covering W3C Reference Library, Modern Server Technology (Jigsaw), and Original Server (CERN server).

\section{IETF}

- The following IETF working groups perform activities related to multimedia.

- Large Scale Multicast Applications (lsma): This WG focuses on the needs of applications that require real-time or near real-time communications to support a large number of simulation processes (virtual entities).

- Audio/Video Transport (AVT): This WG is specifying experimental protocols for real-time transmission of audio and video over UDP and IP multicast. The focus is near-term and its purpose is to integrate and co-ordinate the current AVT efforts of existing research activities.

- Multiparty Multimedia Session Control (mmusic): This WG is developing Internet standards-track protocols to support Internet teleconferencing sessions. To date, MMUSIC has drafted protocols for:

- distributing session descriptions - Session Description Protocol (SDP) and Session Announcement Protocol (SAP),

- providing security for session announcements - SAP Security,

- controlling on-demand delivery of real-time data - Real-Time Stream Protocol (RTSP),

- initiating sessions and inviting users - Session Initiation Protocol (SIP), and

- managing tightly-controlled sessions - Simple Conference Control Protocol (SCCP).

\section{$O M G$}

The Object Management Group or OMG (founded in May 1989) is a non-profit corporation with a commitment to developing technically excellent, commercially viable and vendor independent specifications for the software industry. It now has over 800 members. OMG is developing the "Architecture for a Connected World" through its world wide standard specifications: CORBA/IIOP, Object Services, Internet Facilities and Domain Interface specifications.

Standardisation in the OMG is divided into two technical committees:

- Platform Technology Committee,

- Domain Technology Committee. 
Each has several task forces. From the multimedia viewpoint, the most important task forces are: the Electronic Commerce Domain Task Force and the Telecommunications Domain Task Force, both under supervision of the Domain Technology Committee.

\section{ANSI-T1}

ANSI-T1 is concerned with the specification of access network infrastructures. In particular, ANSI standard T1.413 specifies long range baseband asymmetrical physical interfaces on copper, in particular ADSL. It provides specifications of the modulation scheme (DMT), as well as downstream and upstream frequency ranges and bit-rates. ANSI-T1.413-2 specifies medium range baseband asymmetrical physical interfaces on copper, such as VDSL.

\section{IEEE 802}

IEEE Project 802 has been responsible for the development of most LAN specifications. IEEE has a co-operation agreement with ISO, which allows IEEE standards to be entered into ISO's fast track procedure as candidate ISO International Standards.

The 802.14 Working Group, Standard Protocol for Cable-TV Based Broadband Communication Network, is focusing on standardising both the physical layer modulation scheme for downstream and upstream and the MAC layer protocol for the upstream direction.

\section{How do these activities fit together?}

With such a wide range of activities going on in the different bodies, potential service providers face the daunting task of selecting an suitable profile of standards to ensure interoperability. The ACTS multimedia projects have developed two ways of mapping the activities which should make this task a lot easier.

The first mapping relates standards/specifications production to the various OSI protocol layers. Figure 1 presents the OSI layers in three groups, i.e., the physical layer group, the network and link layers group, and the end-to-end layers group and shows where each of the standards bodies is active.

However multimedia services involve not just a protocol stack but a set of different protocol stacks, which support different sets of functions. This mapping does not therefore show how the different standardisation groups are working to realise protocols capable of supporting the different functions.

The second mapping is based on the following six functions:

- user functions and related protocol stacks, to carry video, audio and data information,

- application control functions and protocol stack, to provide the control of the application; examples would be pause, rewind, book-marking, application protocol selection, and content selection, etc.,

- service control functions, to provide end-to-end brokerage functions between terminals; examples could be yellow-pages searches and selection, address resolution, etc.,

- session control functions, to support the control of communications sessions between user applications, including end-user, network, and third party based applications; it may involve any number of end-users, calls and connections types; additionally, it may provide resource control function, 


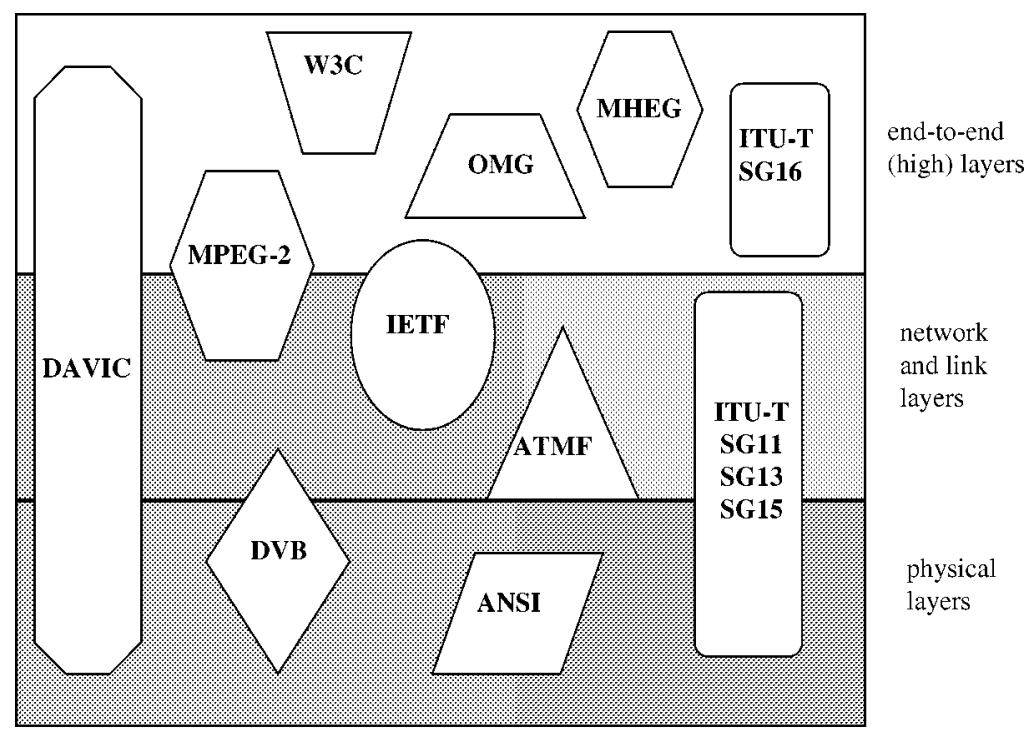

Fig. 1. Standards activities and protocol layers.

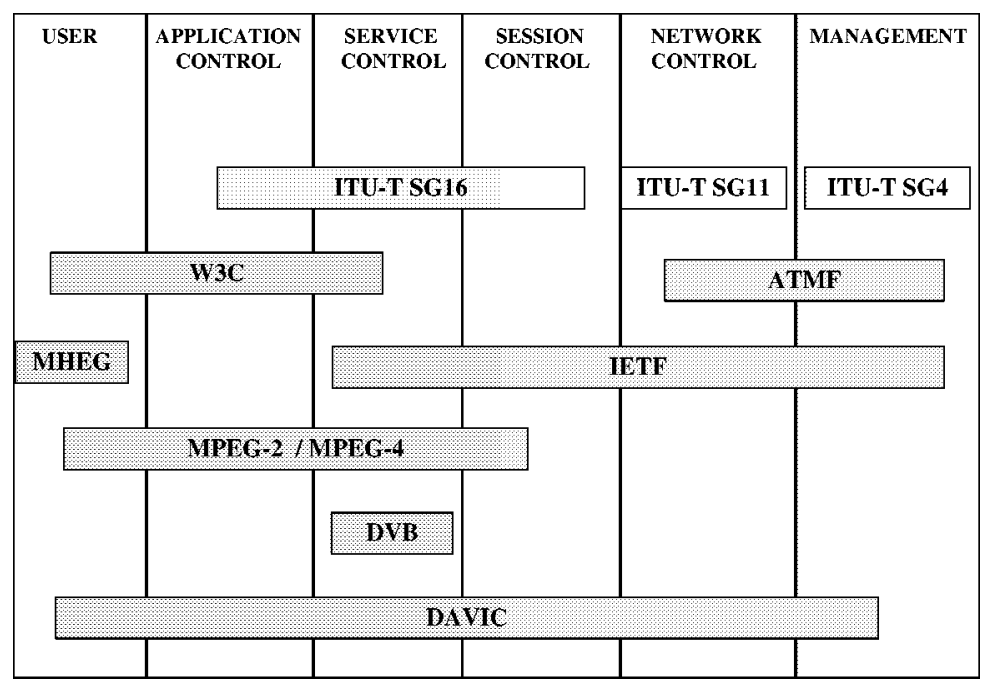

Fig. 2. Standards activities and high layer protocols.

- network control functions, to provide Access, Bearer, Call control functions, plus all intelligent network (IN) functions,

- management functions, to provide management facilities, control and protocols.

These functions have been defined taking into account both the Unified Functional Model defined by ITU-T SG11 and the concept of "DAVIC flows and entities" defined in DAVIC Specs [Part 2, Part 12].

Each function can be implemented using a defined protocol stack. Figure 2 relates the activities of each body/forum to the higher layer protocols. 


\section{Conclusion}

The ACTS guideline 'State of the Art and Evolution of Relevant Standards' explains which aspects of multimedia services are being standardised by the various official and semi-official bodies. It also explains how the various initiatives relate to each other so that potential service developers and providers know where to look for the relevant specifications to ensure interoperability.

Full texts of all ACTS guidelines can be downloaded from

http://www.infowin.org/ACTS/ANALYSYS/CONCERTATION/glindex.htm. 